\title{
Enzymes involved in phthalate degradation in sulphate-reducing bacteria
}

\author{
Robin Alexander Geiger, ${ }^{1}$ Madan Junghare, ${ }^{2}$ \\ Mario Mergelsberg, ${ }^{1}$ Christa Ebenau-Jehle, ${ }^{1}$ \\ Vivien Jill Jesenofsky, ${ }^{1}$ Nico Jehmlich, ${ }^{3}$ \\ Martin von Bergen, ${ }^{3,4}$ Bernhard Schink ${ }^{2}$ and \\ Matthias Boll (10) ${ }^{\text {* }}$ \\ ${ }^{1}$ Faculty of Biology-Microbiology, University of Freiburg, \\ 79104, Freiburg, Germany. \\ ${ }^{2}$ Department of Biology, Microbial Ecology, University of \\ Konstanz, 78457, Constance, Germany. \\ ${ }^{3}$ Department of Molecular Systems Biology, Helmholtz \\ Centre for Environmental Research UFZ, 04318, Leipzig, \\ Germany. \\ ${ }^{4}$ Institute of Biochemistry, Faculty of Life Sciences, \\ University of Leipzig, Brüderstr. 34, 04103, Leipzig, \\ Germany.
}

\section{Summary}

The complete degradation of the xenobiotic and environmentally harmful phthalate esters is initiated by hydrolysis to alcohols and o-phthalate (phthalate) by esterases. While further catabolism of phthalate has been studied in aerobic and denitrifying microorganisms, the degradation in obligately anaerobic bacteria has remained obscure. Here, we demonstrate a previously overseen growth of the $\delta$-proteobacterium Desulfosarcina cetonica with phthalate/sulphate as only carbon and energy sources. Differential proteome and CoA ester pool analyses together with in vitro enzyme assays identified the genes, enzymes and metabolites involved in phthalate uptake and degradation in $D$. cetonica. Phthalate is initially activated to the shortlived phthaloyl-CoA by an ATP-dependent phthalate CoA ligase (PCL) followed by decarboxylation to the central intermediate benzoyl-CoA by an UbiD-like phthaloyl-CoA decarboxylase (PCD) containing a prenylated flavin cofactor. Genome/metagenome analyses predicted phthalate degradation capacity also in the sulphate-reducing Desulfobacula toluolica, strain NaphS2, and other $\delta$-proteobacteria. Our results suggest that phthalate degradation proceeds in all anaerobic bacteria via the labile phthaloyl-CoA that is captured and decarboxylated by highly abundant PCDs. In contrast, two alternative strategies have been established for the formation of phthaloyl-CoA, the possibly most unstable CoA ester in biology.

\section{Introduction}

Phthalic acid esters (PAEs), esters of various alcohols with o-phthalic acid (1,2-dicarboxybenzene, referred to as phthalate), are annually produced at the million ton scale and are mainly used as plasticizers that are noncovalently incorporated into high-molecular weight polymers such as polyvinyl chloride. They are classified as xenobiotics that have been produced industrially only since the 1960s (Giam et al., 1984; Caldwell, 2012; Benjamin et al., 2015; Net et al., 2015; Gao and Wen, 2016). Among many adverse effects, in particular the endocrine disrupting activity of PAEs threatens wildlife and human health. Due to their global utilization and facile migration into the environment during the production, transport and disposal of plastics, PAEs are categorized as industrially important hazardous pollutants (Caldwell, 2012; Benjamin et al., 2015; Gao and Wen, 2016).

Biodegradation of PAEs by microorganisms is considered as the most effective process to eliminate them from the environment (Cousins et al., 2003; Huang et al., 2013; Gao and Wen, 2016). Bacterial PAE degradation is initiated by hydrolysis of the two ester bonds to the corresponding alcohols and phthalate (Liang et al., 2008; Gao and Wen, 2016). In aerobic bacteria, dioxygenases and decarboxylases convert the latter then into protocatechuate, a central intermediate of the aerobic degradation of aromatic compounds (Eaton and Ribbons, 1982; Nomura et al., 1992).

At anoxic habitats, complete oxidation of phthalate to $\mathrm{CO}_{2}$ is considered a rate-limiting step of PAE degradation (Gao and Wen, 2016). The decarboxylation of phthalate to benzoate, either directly or after activation to a CoA thioester, has been proposed more than three decades ago (Taylor and Ribbons, 1983; Nozawa and Maruyama, 1988; Kleerebezem, 1999). However, the genes and enzymes involved in oxygen-independent degradation of phthalate 
were only recently elucidated in studies with denitrifying, phthalate-degrading Thauera, Azoarcus and Aromatoleum strains (Junghare et al., 2016; Ebenau-Jehle et al., 2017). Note that formerly phthalate/aromatic compounds degrading Azoarcus sp. have recently been reclassified to the novel genus Aromatoleum (Rabus et al., 2019). The genomes of denitrifying phthalate degraders contain gene clusters comprising phthalate-induced genes putatively encoding a tripartite ATP-independent periplasmic (TRAP) transporter, a class III CoA-transferase, an UbiD-like decarboxylase, and an UbiX-like prenyltransferase involved in UbiD flavin cofactor maturation. In accordance, extracts of phthalate-grown Thauera chlorobenzoica CB-1, Aromatoleum aromaticum EbN1 and Azoarcus sp. PA01 activated phthalate to phthaloyl-CoA by a succinyl-CoA-dependent CoA transferase, followed by decarboxylation to benzoyl-CoA (Fig. 1) (Junghare et al., 2016; Ebenau-Jehle et al., 2017). In denitrifying bacteria, benzoyl-CoA is dearomatized by ATPdependent class I benzoyl-CoA reductases (Kung et al., 2010; Boll et al., 2014; Buckel et al., 2014; Tiedt et al., 2018). The cyclic dienoyl-CoA product is then converted to three acetyl-CoA and $\mathrm{CO}_{2}$ by modified $\beta$-oxidation reactions of the benzoyl-CoA degradation pathway (Rabus et al., 2005; Fuchs et al., 2011; Schmid et al., 2015; Rabus et al., 2016).

A highly specific, heterodimeric class III succinyl-CoA: phthalate $\mathrm{CoA}$ transferase (SptAB) was characterized from $A$. aromatoleum after heterologous expression in Escherichia coli (Mergelsberg et al., 2018). The product phthaloyl-CoA is extremely labile due to intramolecular substitution yielding CoA and phthalic anhydride (half-life $=7 \mathrm{~min}$ ). To overcome the general problem of phthaloyl-CoA instability, the next enzyme of the pathway, phthaloyl-CoA decarboxylase $(P C D)$ is produced at high amounts in denitrifying phthalate degraders ( $>100 \mu \mathrm{M}, 5 \%-15 \%$ of soluble protein). Thus, phthaloyl-CoA formed by SptAB will be immediately complexed and decarboxylated by PCD, which explains the very low cellular phthaloyl-CoA concentrations far below $1 \mu \mathrm{M}$. No evidence of a direct interaction of SptAB and PCD was observed (Mergelsberg et al., 2018).

A phthaloyl-CoA decarboxylase has so far been isolated only from extracts of $T$. chlorobenzoica cells grown with phthalate and nitrate (Mergelsberg et al., 2017). It belongs to the UbiD-family of (de)carboxylases containing a prenylated FMN (prFMN) and $\mathrm{Fe}^{2+}$ as cofactors. Upon incubation in air, the $\mathrm{Fe}^{2+}$ is oxidized to the $\mathrm{Fe}^{3+}$-state with a concomitant release of the active site prFMN resulting in a complete loss of activity (half-life in air $13.3 \pm 3 \mathrm{~min}$ ). As shown for other UbiD-like decarboxylases, PCD maturation is expected to depend on an UbiX-like prenyltransferase that modifies the active site FMN using dimethylallylmonophosphate as co-substrate (Payne et al., 2015; White et al., 2015). Among UbiD-like decarboxylases, PCD represents the only member catalysing the difficult $\mathrm{C}-\mathrm{C}$ bond cleavage of a non-phenolic arylcarboxyl-CoA thioester. As a consequence, the mechanism is considered to substantially differ from those of recently characterized UbiD-like decarboxylases (Mergelsberg et al., 2017) indicating a functional diversity of UbiD-family members (Leys and Scrutton, 2016; Leys, 2018).

Only very little is known about anaerobic phthalate degradation in strictly anaerobic bacteria. Phthalate degradation coupled to sulphate reduction and methanogenesis was observed in sediment slurries or enrichment cultures (Kleerebezem et al., 1999; Liu and Chi, 2003; Chang et al., 2005; Liu et al., 2005a; Liu et al., 2005b), and Pelotomaculum species were reported to degrade phthalate in syntrophic association with hydrogenotrophic methanogens (Qiu et al., 2006). However, the genes and enzymes involved in phthalate degradation have not yet been studied in an obligately anaerobic organism. Here, we report on the previously unknown capacity of the sulphate-reducing $\delta$-proteobacterium Desulfosarcina cetonica to fully degrade phthalate under sulphate-reducing conditions. This bacterium probably uses the class II benzoyl-CoA reductase for degradation of aromatic compounds and oxidizes the resulting acetyl-CoA through the Wood-Ljungdahl pathway (Janssen and Schink 1995a, b). We identified the genes, enzymes and metabolites involved in the phthalate degradation.

\section{Results and discussion}

Growth of Desulfosarcina cetonica with phthalate and sulfate

The genome of $D$. cetonica contains a gene encoding an UbiD-like product (locus tag JCM12296_RS19395) with

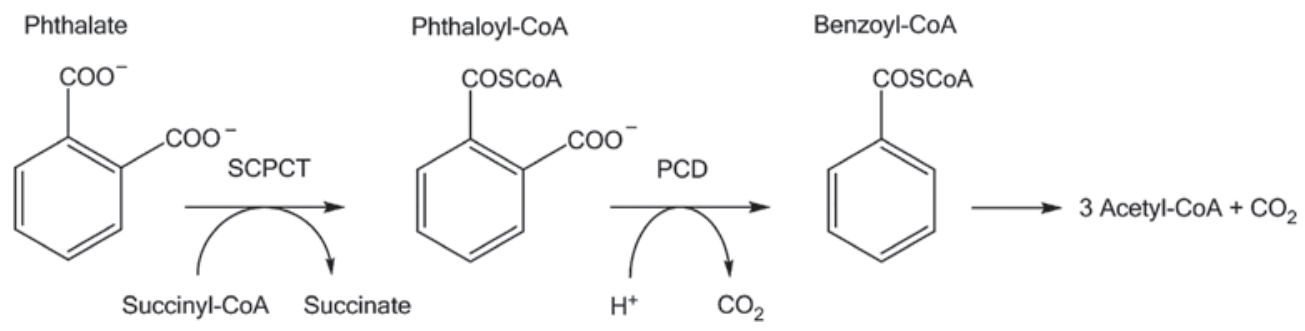

Fig. 1. Enzymatic steps involved in phthalate degradation in denitrifying bacteria. SCPCT = succinyl-CoA:phthalate CoA transferase; $\mathrm{PCD}=$ phthaloyl-CoA decarboxylase. 
marked similarities to the experimentally verified PCD from T. chlorobenzoica (72\% amino acid sequence identity) (Mergelsberg et al., 2017). This finding motivated us to test the phthalate degradation potential of this sulphate-reducing $\delta$-proteobacterium that was originally isolated from a flooded oil stratum (Galushko and Rozanova, 1991). Indeed, during anoxic cultivation in gas-tight sealed $100-\mathrm{ml}$ bottles, the complete degradation of $5 \mathrm{mM}$ phthalate coupled to sulphide production was observed at a doubling time of $36 \pm 3.5 \mathrm{~h}$ with an $\mathrm{OD}_{578}$ reached of around 0.4. The doubling time was slightly higher than during growth with benzoate $(29 \pm 2.5 \mathrm{~h})$, or butyrate $(25 \pm 1.5 \mathrm{~h})$. For large-scale cultivation, $D$. cetonica was grown in a $200 \mathrm{I}$ fermenter (for growth curve see Supporting Information Fig. S1). To remove $\mathrm{H}_{2} \mathrm{~S}$ and to adjust the $\mathrm{pH}$ to 7.4 , this fermenter was frequently gassed with $\mathrm{N}_{2}$ and/or $\mathrm{CO}_{2}$. Under these condition, $1.3 \mathrm{~mol}$ of phthalate were consumed with a yield of $128 \mathrm{~g}$ (wet mass) of $D$. cetonica cells giving a yield coefficient of $Y=0.18 \mathrm{~g}$ (dry mass) per mol phthalate consumed.

\section{In vitro assays for enzymes involved in phthalate degradation}

Due to the instability of phthaloyl-CoA (Mergelsberg et al., 2018), in vitro enzyme assays were routinely carried out in a coupled, discontinuous assay following benzoyl-CoA formation from phthalate by ultra-performance liquid chromatography (UPLC). In the presence of $5 \mathrm{mM}$ MgATP and $0.5 \mathrm{mM} \mathrm{CoA}$, the protein- and time-dependent conversion of phthalate to benzoyl-CoA was observed at a rate of $4.5 \mathrm{nmol} \mathrm{min}{ }^{-1} \mathrm{mg}^{-1}$ (Fig. $2 \mathrm{~A}$ and $B$ ); virtually no phthaloyl-CoA intermediate was detected $(<0.1 \mu \mathrm{M})$. When ATP or CoA was omitted, no formation of benzoyl-CoA was observed. Neither succinyl-CoA nor acetyl-CoA (0.2 mM each) could substitute for CoA + ATP. These results suggest that phthalate is converted to benzoyl-CoA by an ATP-dependent phthalate CoA ligase (PCL) and a $P C D$, whereas no evidence of the involvement of a succinyl-CoA:phthalate CoA transferase, that was identified in all denitrifying, phthalate-degrading bacteria investigated so far, was obtained.

To test the oxygen sensitivity of benzoyl-CoA formation from phthalate, CoA and ATP, extracts of $D$. cetonica cells grown with phthalate/sulphate were incubated in air for different time points on ice after which the activity was measured under anoxic conditions $\left(\mathrm{N}_{2}: \mathrm{H}_{2}, 95: 5\right.$, by vol.). Upon exposure to air, a clear decrease of activity was observed with a half life of around 7 min (Fig. 2C). In contrast the anaerobically incubated control was stable for almost $1 \mathrm{~h}$. While the activation of phthalate to its CoA ester was stable in air (see below), the oxygen sensitivity is assigned to PCD with a half-life being even shorter than that of extracts from $T$. chlorobenzoica cells grown with phthalate/nitrate (20 min) (Mergelsberg et al., 2017).
Formation of benzoyl-CoA from phthalate, CoA and MgATP was negligible in cells grown with benzoate $\left(<0.1 \mathrm{nmol} \mathrm{min}{ }^{-1} \mathrm{mg}^{-1}\right)$, whereas benzoyl-CoA formation from benzoate in the presence of MgATP and CoA was observed in both, cells grown with phthalate or benzoate $\left(4.8 \mathrm{nmol} \mathrm{min}{ }^{-1} \mathrm{mg}^{-1}\right)$. This finding suggests a clear induction of specific PCL/PCD activities during growth with phthalate. To further substantiate the induction of PCD during growth with phthalate, we analysed extracts of exponentially grown cells with phthalate/sulphate and benzoate/ sulphate for the presence of prFMN, the modified flavincofactor of PCD from T. chlorobenzoica (Mergelsberg et al., 2017) and other UbiD-like enzymes. Using ESIQTOF-MS analyses, a compound with $\mathrm{m} / \mathrm{z}=525.1746 \pm$ $0.0008 \mathrm{Da}$ was identified at high abundance in cells grown with phthalate/sulphate that fitted to the catalytically active azomethine ylid (iminium form) of prFMN of UbiD-like enzymes (Payne et al., 2015) including PCD from T. chlorobenzoica (Mergelsberg et al., 2017). In contrast, virtually no compound fitting to this mass was identified in cells grown with benzoate (abundance in phthalate vs benzoate grown cells $\geq 500$ ), which is in line with the differential abundance and activity of PCD in cells grown with phthalate or benzoate (see below).

The dependence on $\mathrm{K}^{+}$ions is a common property of UbiD-like enzymes and was recently also reported also for PCD from T. chlorobenzoica (Mergelsberg et al., 2017). To test whether this applies to PCD from $D$. cetonica, the PCD activity was determined at varying $\mathrm{KCl}$ concentrations. A clear up to 2-fold stimulation of PCD activity was observed in comparison to a control without $\mathrm{KCl}$ supplement with a maximum around $100 \mathrm{mM} \mathrm{KCl}$ (Fig. 2D). In summary, results from cell extracts assays indicate that PCD from $D$. cetonica appears share similar properties with the enzyme from $T$. chlorobenzoica in terms of cofactor content, oxygen-sensitivity, and $\mathrm{KCl}$ dependence.

\section{Rate limiting step during conversion of phthalate to benzoyl-CoA in cell-free extracts}

To determine the individual PCL and PCD activities and thus the rate-limiting step during the conversion of phthalate to benzoyl-CoA, crude cell extract assays were supplemented with fractions of enriched PCL (obtained in this work, see below) or purified PCD from T. chlorobenzoica, respectively. As these fractions contained exclusively either PCL or PCD activity, an increase of the benzoylCoA formation rate should be unambiguously assigned to one of the two enzymes. Addition of enriched PCL (up to $50 \mathrm{nmol} \mathrm{min}{ }^{-1} \mathrm{mg}^{-1}$ crude extract) had virtually no effect on the observed rate of benzoyl-CoA formation from phthalate in the presence of MgATP and CoA. Thus, the observed specific activity of $4.5 \mathrm{nmol} \mathrm{min}{ }^{-1} \mathrm{mg}^{-1}$ can be assigned to PCD, catalysing the rate-limiting step during 

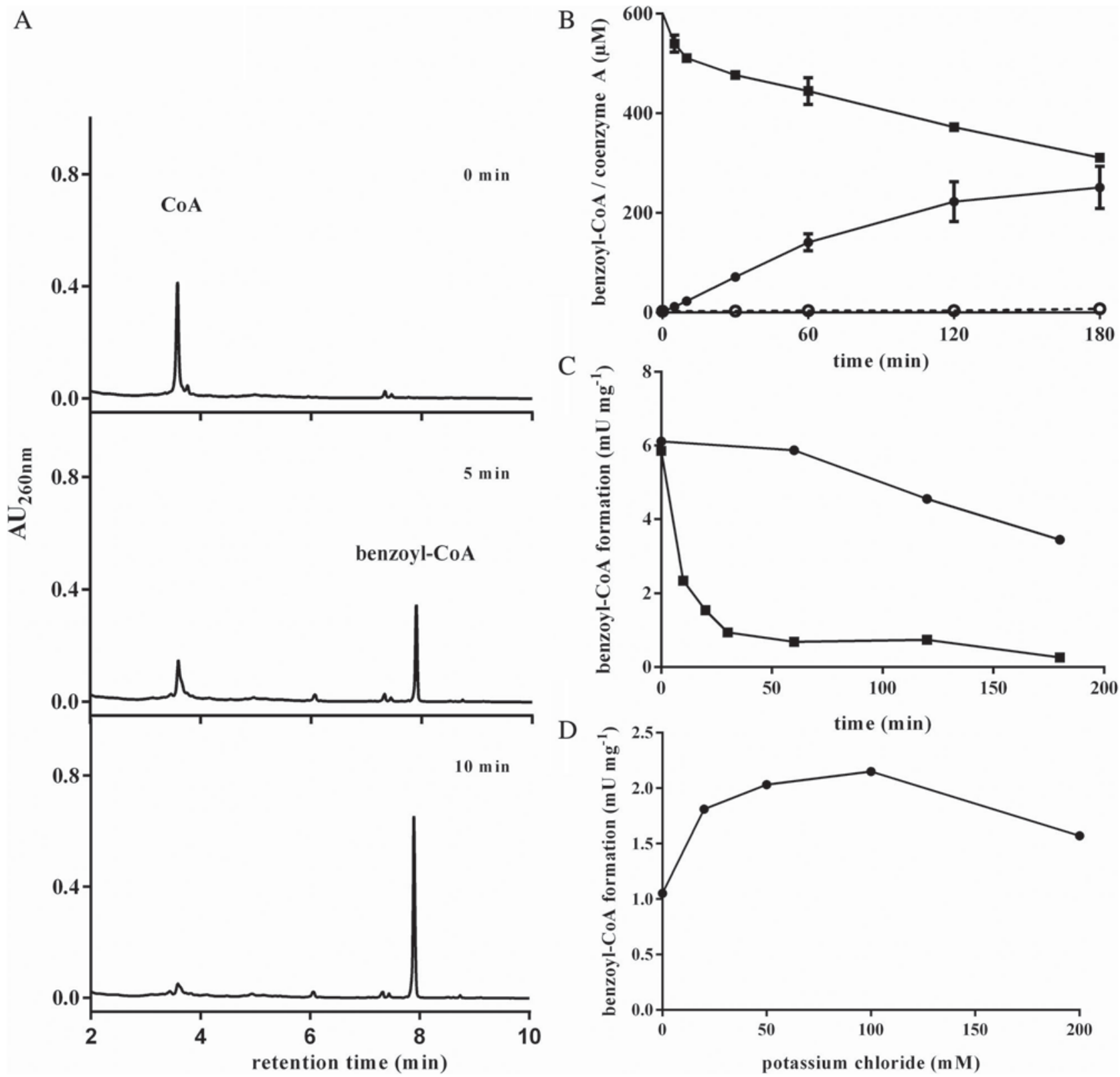

Fig. 2. In vitro conversion of phthalate to benzoyl-CoA and properties of PCD.

A. UPLC-analysis of the time-, phthalate-, and ATP-dependent conversion of CoA to phthaloyl-CoA by extracts of $D$. cetonica cells grown with phthalate/sulphate. Virtually to transient accumulation of the proposed phthaloyl-CoA intermediate was observed.

B. Course of $\operatorname{CoA}(\square)$ consumption, and benzoyl-CoA $(\mathbf{0})$ formation in the presence of phthalate; $(O)$ benzoyl-CoA formation in the absence of phthalate.

C. Oxygen sensitivity of benzoyl-CoA formation from phthalate and CoA; crude extract $(\boldsymbol{\square})$ incubated in air at $4{ }^{\circ} \mathrm{C},(\bullet)$ incubated under anoxic conditions at $4{ }^{\circ} \mathrm{C}$

D. $\mathrm{KCl}$ dependence of the benzoyl-CoA formation from phthalate and $\mathrm{CoA}$.

the conversion of phthalate to benzoyl-CoA. In contrast, the addition of increasing amounts of PCD gradually stimulated the rate of benzoyl-CoA formation reaching a maxi-

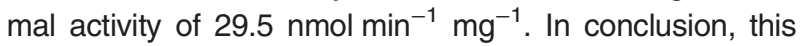
activity is assigned to PCL activity in cell extracts of D. cetonica.

The phthaloyl-CoA forming and decarboxylating activities in $D$. cetonica crude extracts were in the range of the corresponding activities reported for extracts of denitrifying phthalate degraders (18-31 nmol $\mathrm{min}^{-1} \mathrm{mg}^{-1}$ for succinylCoA:phthalate CoA transferase and 6-13 nmol $\mathrm{min}^{-1} \mathrm{mg}^{-1}$ for phthaloyl-CoA decarboxylase activities) (Ebenau-Jehle et al., 2017).

A phthalate-induced gene cluster in D. cetonica and similar clusters in other sulphate-reducing bacteria. A 
whole genome shotgun sequence of $D$. cetonica is available (accession Nr. NZ_BBCC00000000). To identify genes and proteins specifically involved in phthalate degradation, extracts of $D$. cetonica cells grown with phthalate/sulphate were subjected to mass spectrometry (MS)based proteome analyses and compared with those from cells grown with benzoate/sulphate and butyrate/sulphate (for proteome data see Supporting Information Tables S1 and S2). By analysing six biological replicates, the PCDlike gene product with the locus tag JCM12296_RS19395 was identified at a 740 -fold higher abundance in cells grown with phthalate than in cells grown with benzoate as carbon and electron source. Proteins that were only identified in $D$. cetonica cells grown with phthalate but not in cells grown with benzoate or butyrate comprise putative gene products with amino acid sequence similarities to the respective phthalate-induced gene products from T. chlorobenzoica including a UbiX-like prenyltransferase (83\% identity), a TRAP transporter (85\% identity) and a periplasmic binding protein ( $96 \%$ identity). A further gene product uniquely identified in cells grown with phthalate is assigned to a putative AMP-forming, long chain fatty acid CoA ligase (JCM12296_RS19390) fitting perfectly to the observed ATP-dependent benzoyl-CoA formation from phthalate and CoA in crude extracts of $D$. cetonica. Neither in cells grown with phthalate nor with benzoate, a gene product for a SptAB-like class III CoA transferase was identified.

The phthalate-induced genes of $D$. cetonica are organized in a single cluster (Fig. 3A). Next to the phthalateinduced gene products identified by proteome analyses, additional putative gene products of this cluster are annotated as kinase inhibitor, stress protein and flavindependent dehydrogenase/isomerase. Their role is less clear but they may be involved in regulatory processes and/or cofactor maturation.

We searched in genomes from other known strictly anaerobic sulphate reducing, metal oxide reducing or fermenting bacteria for similar gene clusters using the UbiD-like putative phthaloyl-CoA decarboxylase from D. cetonica (JCM12296_RS19395) as query sequence. In the completed genome of the sulphate-reducing Desulfobacula toluolica Tol2 (Wöhlbrand et al., 2013, accession Nr. NC_018645.1), a highly similar gene cluster was identified, that, possibly as a result of an artefact during genome assembly was present five identical copies (Fig. 3B). The cluster contains all genes present in the phthalate-induced gene cluster of $D$. cetonica including the encoding gene of a putative UbiD-like decarboxylase (TOL2_RS14825) with $83 \%$ amino acid sequence identity to the corresponding gene product from D. cetonica (JCM12296_RS19395). Based on theses finding, $D$. toluolica is proposed to have the capacity to degrade phthalate employing similar gene products that are hitherto similar to those of $D$. cetonica. Using BLAST a putative PCD-like decarboxylase was identified also in the genome of the naphthalene degrading, sulphate-reducing strain NaphS2 (WP_006419763.1, 84\% identity) (Musat et al., 2009; DiDonato Jr. et al., 2010). However, no other gene typical of anaerobic phthalate degradation was identified in the near genomic environment. Notably, naphthalene degradation is initiated by naphthalene carboxylation, catalysed by a further UbiD-like enzyme present in sulphate-reducing bacteria during growth with aromatics (Koelschbach et al., 2019). No other clearly significant homologue of PCD (amino acid sequence identity $\geq 65 \%$ ) was identified in the genomes of other strictly anaerobic bacteria that are known to have the enzyme inventory of the benzoyl-CoA degradation pathway. However, a number of $\delta$-proteobacterial PCD homologues (amino acid sequence identity $\geq 66 \%$ ) were identified in the metagenomes of a shallow sediment-hosted perennially suboxic/oxic aquifer (Anantharaman et al., 2016), (Supporting Information Table S3), suggesting that next to $D$. cetonica, $D$. toluolica and NaphS2, many so far unknown strictly anaerobic $\delta$-proteobacteria have acquired the capability of phthalate degradation.

\section{Enrichment and some properties of enriched phthalate CoA ligase}

The results of in vitro enzyme assays and of proteome analyses suggest that in sulphate-reducing bacteria phthalate is activated by a phthalate CoA ligase (PCL) instead of a succinyl-CoA dependent CoA transferase present in denitrifying phthalate degraders. To separate PCL from PCD and other potential acyl-CoA synthetases $100,000 \times g$ supernatants of extracts of $D$. cetonica cells grown with phthalate/sulphate in a 200 I fermenter were subjected to DEAE Sepharose anionic exchange chromatography under anoxic conditions. PCL activity assays were routinely supplemented with PCD from T. chlorobenzoica $\left(130 \mathrm{nmol} \mathrm{min} \mathrm{ml}^{-1}\right)$ and the MgATP and CoA-dependent formation of benzoyl-CoA was followed by UPLC. If necessary, the amount of PCD added in the assays was adjusted to guarantee that PCL but not PCD activity was rate limiting in the coupled assay. After a wash step with $35 \mathrm{mM} \mathrm{KCl}$ in morpholino propanesulfonic acid (Mops) buffer at $\mathrm{pH} 7.8, \mathrm{PCL}$ activity was eluted in buffer containing $85 \mathrm{mM} \mathrm{KCl}$ in with a 3.2-fold enrichment and a yield of $4.5 \%$ (Table 1). SDS PAGE analysis of the PCL activity fraction did not reveal an enriched band migrating at the deduced mass ( $52 \mathrm{kDa})$ of the putative phthalate-induced carboxylic acid CoA ligase (JCM12296_RS19390, not shown) suggesting that PCL represents a rather low abundant enzyme with a high specific activity. All attempts to further enrich PCL by other chromatographic materials including Q-Sepharose anionic 

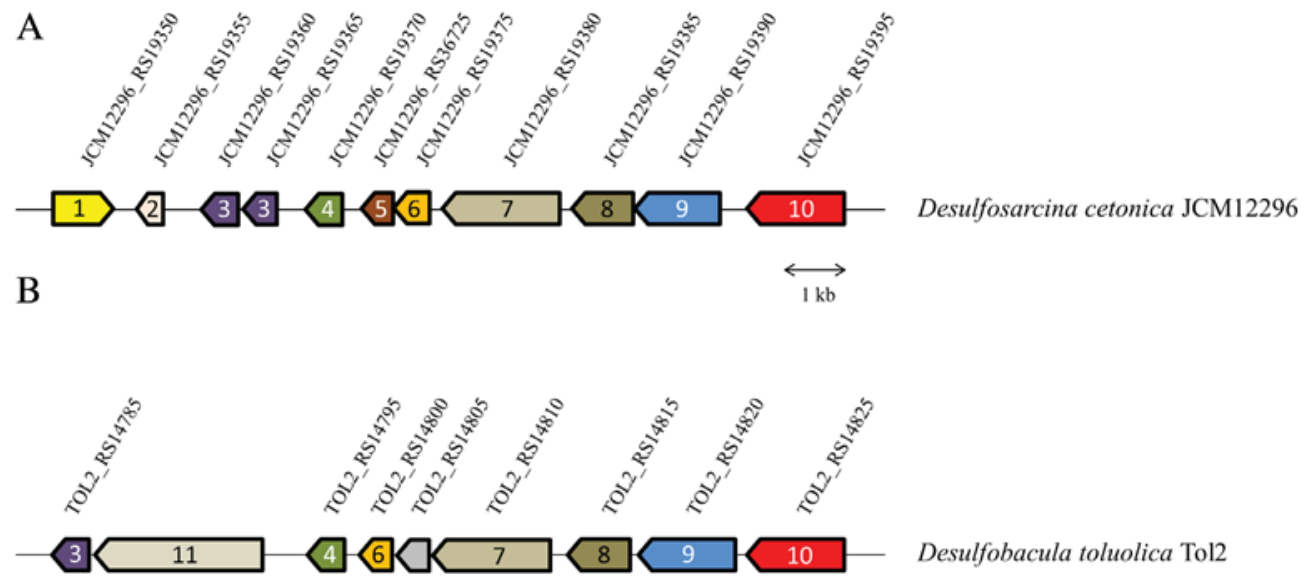

Fig. 3. Phthalate-induced gene cluster in $D$. cetonica as identified by differential proteome analyses and similar genes in Desulfobacula toluolica. A. Phthalate-induced genes in D. cetonica. 1, Transcriptional regulator; 2, flavin reductase-like protein; 3 , FMN-dependent dehydrogenase/ isomerase; 4, UbiX-like enzyme; 5, putative kinase inhibitor; 6, putative nucleotide-binding protein; 7, TRAP transporter; 8, periplasmic binding protein; 9, longchain fatty acid CoA ligase; 10 , UbiD-like (de)carboxylase. The gene products 4, 7-10 were identified as phthalate induced during proteome analyses.

B. Similar gene cluster in D. toluolica. Similar colour/numbers indicate high amino acid sequence similarities and predicted similar functions. [Color figure can be viewed at wileyonlinelibrary.com]

exchanger, a number of reactive dye resins for affinity chromatography, or gel filtration were always accompanied with a major or complete loss of PCL activity without any further enrichment.

Using the PCL activity containing fractions obtained after chromatography on DEAE Sepharose, phthalate + CoA conversion to benzoyl-CoA followed MichaelisMenten kinetics with an apparent $K_{\mathrm{m}}$ of $22.5 \pm 2.8 \mu \mathrm{M}$ for phthalate (Supporting Information Fig. S2). Notably this fraction contained virtually no benzoate CoA ligase activity indicating that a specific PCL but no promiscuous benzoate $\mathrm{COA}$ ligase catalysed phthalate activation. Enriched PCL was stable in air; virtually no loss of activity was observed compared to an anaerobically incubated control for several hours at $4{ }^{\circ} \mathrm{C}$ or for weeks in liquid nitrogen.

\section{Enrichment and properties of phthaloyl-CoA} decarboxylase

Enrichment of PCD activity from crude extracts from $D$. cetonica grown with phthalate/sulphate was carried out by DEAE anion exchange chromatography under anoxic conditions. Using the same buffer as for PCL enrichment plus $10 \%$ glycerol, PCD activity eluted at $75 \mathrm{mM} \mathrm{KCl}$ with an almost five-fold enrichment and a yield of $4.4 \%$ (Table 1). Similar as for PCL, all attempts for further enrichment by the chromatographic methods did not result in a further enrichment of PCD. Thus, PCL and PCD appear to be far less stable than the phthaloyl-CoA forming/decarboxylating enzymes from denitrifying bacteria (Mergelsberg et al., 2017; Mergelsberg et al., 2018).

SDS-PAGE analysis of the protein fractions obtained after DEAE chromatography during PCD enrichment revealed a dominant band migrating at around $60 \mathrm{kDa}$ (Fig. 4), fitting to the theoretical mass of the putative PCD (JCM12296_RS19395). UPLC/electrospray-ionizationquadrupole-time-of-flight mass spectrometry (ESI-QTOFMS) analyses of tryptic digests of the excised protein band unambiguously identified it as JCM12296_RS19395 (95.7\% sequence coverage).

\section{Differential intracellular CoA ester pool analyses}

To identify accumulating metabolites during phthalate degradation in $D$. cetonica, CoA esters were extracted from cells grown exponentially with phthalate or benzoate

Table 1. Enrichment of phthalate CoA ligase $(\mathrm{PCL})$ and phthaloyl-CoA decarboxylase (PCD) from extracts of $D$. cetonica cells grown with phthalate and sulphate on DEAE anion exchange chromatography. PCL was purified from $1.6 \mathrm{~g}$, PCD from $3.5 \mathrm{~g}$ (wet mass, respectively).

\begin{tabular}{lccccc}
\hline Enzyme/Enrichment step & $\begin{array}{l}\text { Total } \\
\text { protein }(\mathrm{mg})\end{array}$ & $\begin{array}{l}\text { Total activity } \\
\left.(\mathrm{nmol} \mathrm{min})^{-1}\right)\end{array}$ & $\begin{array}{l}\text { Specific activity } \\
\left(\mathrm{nmol} \mathrm{min} \mathrm{mg}^{-1}\right)\end{array}$ & $\begin{array}{l}\text { Enrichment } \\
(- \text { fold })\end{array}$ & \begin{tabular}{l} 
Recovery $(\%)$ \\
\hline$P C L$
\end{tabular} \\
$100.000 \times g$ supernatant & 98 & 2892 & 29.5 & 1 & 100 \\
DEAE-Sepharose & 1.4 & 133 & 95 & 3.2 & 4.5 \\
$P C D$ & 350 & 1190 & 3.4 & 1 & 100 \\
$100.000 \times g$ supernatant & 3.1 & 52.7 & 17 & 5 & 4.4 \\
DEAE-Sepharose & & &
\end{tabular}


$\left(\mathrm{OD}_{578}\right.$ between 0.1 and 0.2$)$; 2-chlorobenzoyl-CoA was added at defined amounts as an external reference standard. LC/ESI-Q-TOF-MS analyses revealed that benzoylCoA was clearly the most abundant CoA-ester in extracts of cells grown with phthalate or benzoate, followed by acetyl-CoA (other typical CoA esters of the benzoyl-CoA degradation pathway identified at lower concentrations are not listed here) (Fig. 5). In contrast, not even traces of phthaloyl-CoA were detected (cellular concentration $<0.1 \mu \mathrm{M}$ ). These findings are in agreement with results from previous studies of phthalate-degrading denitrifying bacteria where phthaloyl-CoA was also identified only in trace amounts (Mergelsberg et al., 2018). Remarkably, the abundance of succinyl-CoA was below the detection limit $(<0.1 \mu \mathrm{M})$ under both growth conditions. This finding is in accordance with the absence of a gene encoding a putative succinyl-CoA:phthalate CoA transferase in the phthalate induced gene cluster in sulphate-reducing bacteria. In contrast, succinyl-CoA represents a highly abundant CoA ester in phthalatedegrading denitrifying bacteria and serves as CoA donor for a phthalate induced CoA transferase (Junghare et al., 2016; Ebenau-Jehle et al., 2017; Mergelsberg et al.,

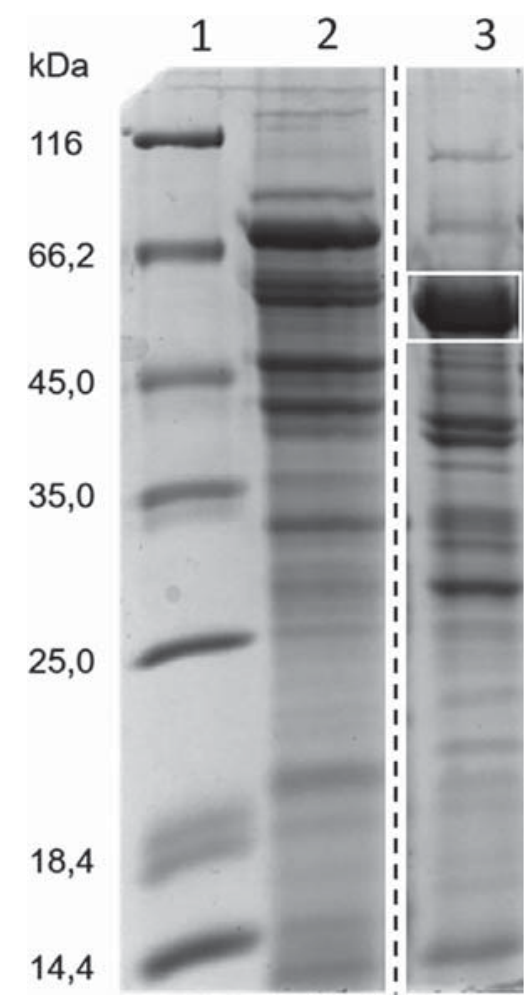

Fig. 4. SDS gel demonstrating enrichment of $P C D$ from extracts of D. cetonica cells grown with phthalate and sulphate. Lane 1, molecular weight standard; lane 2, $100,000 \times g$ supernatant; lane 3 , protein fraction eluting at $75 \mathrm{mM} \mathrm{KCl}$ during $\mathrm{DEAE}$ anion exchange chromatography. The framed protein band at around $60 \mathrm{kDa}$ was identified by mass spectrometry as JCM12296_RS19395 with $72 \%$ amino acid sequence identity to PCD from $T$. chlorobenzoica.

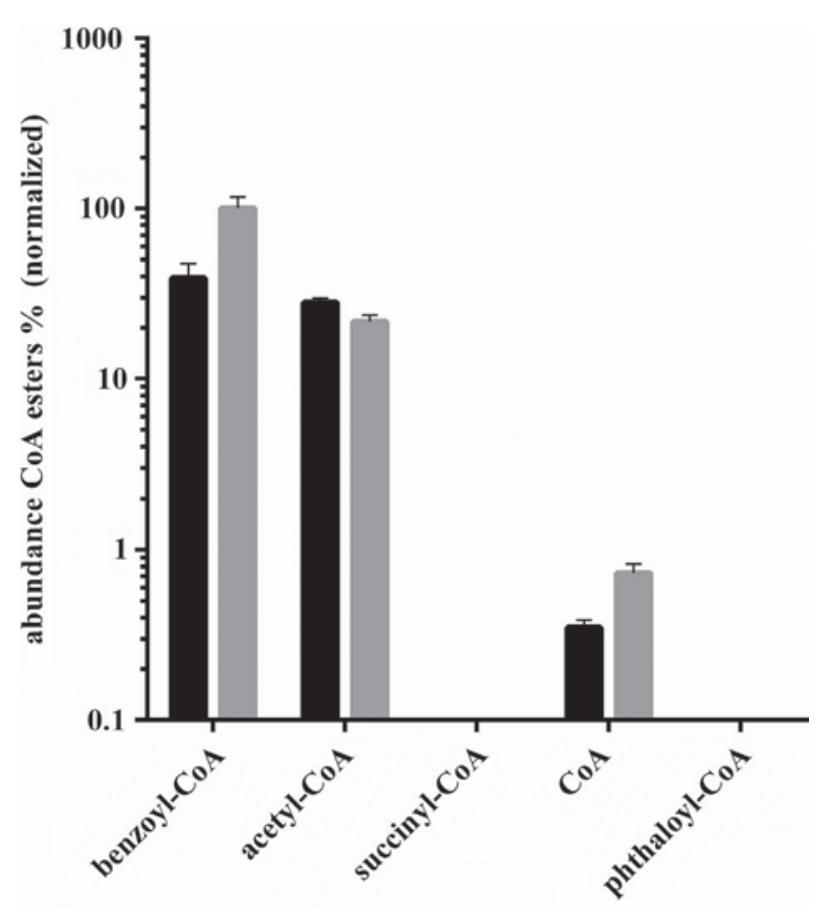

Fig. 5. Cellular abundance of CoA esters. CoA esters were identified by UPLC/ESI-Q-TOF MS analysis. Black bars: cells grown with phthalate; grey bars: cells grown with benzoate. Values were normalized to the highest abundant CoA ester benzoyl-CoA (100\%), abundance of succinyl-CoA and phthaloyl-CoA was $\leq 0.1 \%$ of benzoyl-CoA.

2018). The inability to detect phthaloyl-CoA is assigned to its reported instability which after its formation affords an immediate complexation and decarboxylation by the highly abundant PCD, which prevents its accumulation and subsequent decay (Mergelsberg et al., 2018).

\section{Conclusions}

Until recently, the pathway of oxygen-independent phthalate degradation has been studied exclusively in a number of denitrifying bacteria of the genera Thauera and Aromatoleum. The previously overseen capacity of $D$. cetonica to use phthalate as carbon/energy source opened the door to identify the genes and study the enzymatic reactions involved in phthalate degradation in an obligately anaerobic model organism. The results obtained suggest that anaerobic phthalate degradation follows similar strategies in denitrifying and sulphatereducing bacteria: phthalate is initially activated to the extremely labile phthaloyl-CoA that serves as a substrate for a highly abundant PCD, which immediately captures and decarboxylates it to benzoyl-CoA, thereby preventing futile decay to phthalate and CoA. Next to the encoding genes for catabolic enzymes, also those involved in phthalate uptake and PCD maturation appear to be highly similar in nitrate- and sulphate-reducing bacteria. 
The only but remarkable exception is the phthalate activation step: while all denitrifying bacteria investigated so far use a class III succinyl-CoA:phthalate CoA transferase, $D$. cetonica and most probably $D$. toluolica use an ATP-dependent phthalate CoA ligase. At the first view, it appears surprising that sulphate-reducing bacteria that gain far less energy from complete degradation of aromatic substrates than denitrifyers do (Rabus et al., 1993; Peters et al., 2004) activate phthalate by an AMP-forming CoA ligase instead of a less energy-consuming succinylCoA-dependent CoA transferase. However, the inability to detect succinyl-CoA in $D$. cetonica during growth with phthalate clearly indicates that this organism oxidizes the three acetyl-CoA formed from phthalate in the benzoyl$\mathrm{CoA}$ degradation pathway completely to six $\mathrm{CO}_{2}$ not via the citric acid cycle but via the Wood-Ljungdahl pathway as reported for most alcohols/fatty acid oxidizing sulphate-reducing bacteria (Schauder et al., 1986; Janssen and Schink, 1995b). Thus, the use of a succinylCoA-dependent CoA transferase is no option for sulphate-reducing bacteria. It is remarkable that despite the relatively short period since PAEs have been introduced at the industrial and thus environmentally relevant scale, obviously two non-related enzymatic strategies have evolved for the initiation of phthalate degradation.

The capacity to use phthalate as growth substrate appears to be less abundant under sulphate- than under nitrate-reducing conditions, though putative PCD encoding genes were identified in unknown $\delta$-proteobacteria during metagenomic aquifer analyses (Anantharaman et al., 2016). A rational explanation for this observation may be that xenobiotic PAEs have predominantly been released to the environment at terrestric sites as a result of urbanization and industrialization, and less in marine sediments where sulphate respiration represents the major form of energy metabolism (Gao and Wen, 2016). It can be speculated whether the ongoing pollution of marine environments by plasticizer-containing plastics (Bergmann et al., 2017; Haward, 2018) will probably result in a higher frequency of the capability to fully degrade phthalate among marine sulphate-reducing bacteria. Surprisingly, no phthalate catabolic gene cluster was found in the genomes of obligately anaerobic Fe(III)-respiring or fermenting bacteria with sequenced genomes (e.g. Geobacter or syntrophic fermenting species). Within the latter physiological group, Pelotomaculum isophthalicum is the only reported phthalate-degrading pure culture (Qiu et al., 2006). Recently, isophthalate degradation was shown to follow principles in syntrophically fermenting Syntrophorhabdus aromaticivorans that are similar to phthalate degradation in sulphate-reducing bacteria involving an ATP-dependent isophthaloyl-CoA synthetase and a UbiD-like isophthaloyl-CoA decarboxylase (Junghare et al., 2019).

\section{Experimental procedures}

\section{Cultivation of D. cetonica and preparation of cell-free extracts}

Desulfosarcina cetonica strain 480 (JCM12996, DSM7267) (Galushko and Rozanova, 1991) was grown anaerobically in bicarbonate-buffered mineral salt medium at $30{ }^{\circ} \mathrm{C}$ in a 200 I bioreactor (GEA Diessel $\mathrm{GmbH}$, Hildesheim) containing an initial concentration of $5 \mathrm{mM}$ phthalate and $20 \mathrm{mM} \mathrm{Na}_{2} \mathrm{SO}_{4}$. The bioreactor was operated in a continuous fed-batch mode using a $0.25 \mathrm{M}$ phthalate and $1 \mathrm{M} \mathrm{Na}_{2} \mathrm{SO} 4$ stock solution. Cells were harvested in the exponential growth phase at $\mathrm{OD}_{578}=0.7$. Harvested cells were kept frozen in liquid nitrogen until use.

Cells used for proteome analysis were grown anaerobically in 80-ml medium containing $10 \mathrm{mM}$ butyrate, $5 \mathrm{mM}$ benzoate or $5 \mathrm{mM}$ phthalate as carbon and energy source in addition to $20 \mathrm{mM} \mathrm{Na}_{2} \mathrm{SO}_{4}$ as electron acceptor. Cells were harvested in the exponential growth phase at an $\mathrm{OD}_{578}$ of $0.14-0.2$, centrifuged (10 min, $20.800 \times g, 4^{\circ} \mathrm{C}$ ) and washed twice with $10 \mathrm{mM}$ Tris/ $\mathrm{HCl}(\mathrm{pH} 7)$. The pellets obtained were frozen in liquid nitrogen until proteome analysis. Extracts were prepared under anaerobic conditions. Frozen cells were suspended in a three- to four-fold volume of $20 \mathrm{mM}$ potassium phosphate buffer $(\mathrm{pH} 8)$ for in vitro assays. In case of PCD enrichment, cell suspension was in buffer A (50 mM MOPS, $50 \mathrm{mM} \mathrm{KCl}$, glycerol $10 \% \mathrm{v} / \mathrm{v}$, DTE $1 \mathrm{mM}, \mathrm{pH} 7.5)$. Buffers were supplemented with $0.1 \mathrm{mg} \mathrm{mL}^{-1}$ DNase I, $0.1 \mathrm{mg} \mathrm{mL}^{-1}$ RNase $A$, and $0.1 \mathrm{mg} \mathrm{mL}^{-1}$ lysozyme. Cell suspensions were passed through a chilled French pressure cell at $9 \mathrm{MPa}$. The cell lysate was ultra-centrifuged $\left(1 \mathrm{~h}, 200.000 \times g, 4^{\circ} \mathrm{C}\right)$ and the supernatant was used immediately. In case of PCL enrichment, cells were suspended in buffer $A(50 \mathrm{mM}$ MOPS, $10 \mathrm{mM} \mathrm{KCl}, \mathrm{pH}$ 7.8) containing $0.1 \mathrm{mg} \mathrm{mL}^{-1}$ DNase I and $0.1 \mathrm{mg} \mathrm{mL}^{-1}$ RNase A. Cells were lysed by incubating suspension for $1 \mathrm{~h}$ with lysozyme $1 \mathrm{mg} \mathrm{g}^{-1}$ cells followed by ultra-centrifugation as described above.

\section{LC analyses coupled to MS and UV/Vis detection}

Metabolites were analysed by LC/MS using a Waters Acquity I-class UPLC with a Waters C18 HSS T3 column (2.1 $\mathrm{mm} \times 100 \mathrm{~mm}, 1.8-\mu \mathrm{m}$ particle size) coupled to a Waters Synapt G2-Si HDMS ESI/Q-TOF system. For analysis of CoA thioesters, an 8 min linear gradient of $2 \%$ to $30 \%$ acetonitrile in $10 \mathrm{mM}$ ammonium acetate $\mathrm{pH} 6.8$ at a flow rate of $0.35 \mathrm{ml} \mathrm{min}^{-1}$ was applied. For analysis of prFMN/FMN, a 20 min linear gradient of $5 \%$ to $25 \%$ acetonitrile/ $0.1 \%$ formic acid $(\mathrm{v} / \mathrm{v})$ in water/0.1\% formic acid (v/v) was used at a flow rate of $0.35 \mathrm{ml} \mathrm{min}^{-1}$. Both, CoA esters and $\mathrm{prFMN/FMN}$ were measured in MS positive mode with a capillary voltage of $3 \mathrm{kV}, 150^{\circ} \mathrm{C}$ source temperature, $450{ }^{\circ} \mathrm{C}$ desolvation temperature, $1000 / \mathrm{min}^{-1} \quad \mathrm{~N}_{2}$ 
desolvation gas flow and $100 \mathrm{I} \mathrm{min}^{-1} \mathrm{~N}_{2}$ cone gas flow. Collision induced dissociation of precursor ions was performed using a collision energy ramp from 10 to $50 \mathrm{~V}$. LC analyses coupled to UV/visible detection using a Waters Acquity photo diode array detector were conducted with a Waters Acquity $\mathrm{H}$-class UPLC with a Knauer Eurospher 100-2 C18 column ( $2 \mathrm{~mm} \times 100 \mathrm{~mm}, 2-\mu \mathrm{m}$ particle size). CoA esters were separated using a $10 \mathrm{mM}$ potassium phosphate buffer $\mathrm{pH} 7.0$ applying the same gradient and same flow rate as described above for MS-based analyses. Evaluation of LC/MS metabolite data was performed using MassLynx (Waters); for evaluation of LC-UV/visible data MassLynx or Empower (Waters) was used.

For protein identification, protein bands from SDSPAGE were excised, cysteine residues were reduced using dithiothreitol and alkylated by treatment with iodoacetamide. After in-gel digestion with trypsin (SigmaAldrich), the resulting peptides were separated on a Waters Acquity I-class UPLC with a Waters Peptide CSH C18 column $(2.1 \mathrm{~mm} \times 150 \mathrm{~mm}, 1.7-\mu \mathrm{m}$ particle size $)$ with a gradient from $1 \%$ to $40 \%$ ACN $/ 0.1 \%$ formic acid $(\mathrm{v} / \mathrm{v})$ in water/0.1\% formic acid $(\mathrm{v} / \mathrm{v})$ at a flow rate of $0.04 \mathrm{ml} \mathrm{min}^{-1}$. The source conditions used were the same as described above except that the source temperature was lowered to $80^{\circ} \mathrm{C}$, the desolvation temperature to $400{ }^{\circ} \mathrm{C}$ and the desolvation gas flow to $800 \mathrm{I} \mathrm{h}^{-1}$. The instrument was operated in positive HD-MSE mode. The resulting spectra were analysed with ProteinLynx Global Server (Waters) by matching with the UniProt database (minimal fragment ion matches per peptide $=3$, minimal fragment ion matches per protein $=3$, minimal peptide matches per protein $=7$, false discovery rate $3 \%$ ).

\section{Enzyme assays}

Coupled, discontinuous PCL activity assays were performed in a glove box $\left(95 \% \mathrm{~N}_{2}, 5 \% \mathrm{H}_{2}\right)$ at $30{ }^{\circ} \mathrm{C}$ in $100 \mathrm{mM}$ potassium phosphate buffer $(\mathrm{pH} 8)$. It followed the PCD (isolated from Thauera chlorobenzoica grown phthalate) (Mergelsberg et al., 2017), phthalate (0.5 mM), $\operatorname{MgATP}(5 \mathrm{mM})$ and CoA $(0.5 \mathrm{mM})$-dependent formation of benzoyl-CoA by UPLC coupled to diode array detection at $260 \mathrm{~nm}$ as described (Mergelsberg et al., 2017). For detecting maximal PCL activities, PCD was added at saturating amounts to guarantee that only PCL was ratelimiting during benzoyl-CoA formation from phthalate and CoA. Coupled PCD activity assay was performed under the identical conditions. Here, PCD activity-free, enriched $\mathrm{PCL}$ from $D$. cetonica was used as phthaloyl-CoA synthesizing enzyme. Prior detection of PCD activities, the required saturating $P C L$ activity to be added was determined in control experiments. For all assays proteins were precipitated in $0.9 \mathrm{M} \mathrm{HCl} / 10 \%$ acetonitrile (v/v). Product formation was quantified based on calibration curves of standards. Oxygen inactivation was tested by pre-incubating cell-free extracts in the presence or absence of oxygen at $4{ }^{\circ} \mathrm{C}$. The assay was then performed in the absence of oxygen and started with coenzyme A. Potassium dependence was tested using $20 \mathrm{mM}$ Tris $/ \mathrm{HCl}(\mathrm{pH}$ 8) buffer instead of $100 \mathrm{mM}$ potassium phosphate buffer and varying concentrations (0-200 mM) of potassium chloride.

\section{Enrichment of $P C D$ and $P C L$}

All steps were carried out under anoxic conditions (95\% $\mathrm{N}_{2}, 5 \% \mathrm{H}_{2}$ ). Around $3 \mathrm{~g}$ of phthalate grown cells (wet mass) were suspended in 9-12 $\mathrm{ml}$ buffer $\mathrm{A}$ and lysed using a French pressure cell. After ultracentrifugation, the supernatant was filtered through a $0.2-\mu \mathrm{m}$ sterile filter (Filtropur $\mathrm{S}$ 0.2 , Sarstedt) and applied to a $12 \mathrm{ml}$ DEAE-Sepharose column (GE Healthcare), equilibrated with buffer $A$ at a flow rate of $0.5 \mathrm{ml} \mathrm{min}^{-1}$. The column was washed with two bed volumes of buffer $A$ and with buffer $A$ supplemented with $15 \mathrm{mM} \mathrm{KCl}(\mathrm{PCD})$ or $20 \mathrm{mM} \mathrm{KCl}(\mathrm{PCL})$. Fractions eluting in buffer $\mathrm{A}$ at higher $\mathrm{KCl}$ concentrations as indicated in the results section were tested for PCL/PCD activities. Activity containing fractions were concentrated and used for SDSPAGE analysis and enzymatic assays. Other chromatography materials tested for PCL/PCD enrichment were Resource Q-Sepharose anionic exchanger, Superdex 200 10/300 Gl gel filtration (all GE Healthcare), and the affinity dyes Reactive Green 5 Agarose, Reactive Red 120, and Cibacron Blue 3GA (1 ml columns each, all Sigma-Aldrich). All columns were equilibrated with buffer $\mathrm{A}$, and elution was by varying $\mathrm{KCl}$, or in case of the affinity dyes, phthalate concentrations $(0.1-1 \mathrm{M})$.

\section{Extraction of COA esters and prFMN for MS analyses}

Intracellular CoA esters and intracellular prenylated FMN were extracted from $100 \mathrm{ml} D$. cetonica cells in exponential growth phase with an $\mathrm{OD}_{578}$ 0.1-0.2. Cells were harvested through filtration with regenerated cellulose filters $0.2 \mu \mathrm{m}$ (Sartorius). Filters were prewashed in a vol-

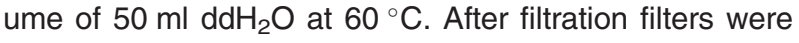
treated twice with ultrasonic in 10-ml extraction solution (0.1 M formic acid, $80 \%$ acetonitrile (v/v). Filters were washed with $2 \mathrm{ml}$ of extraction solution afterwards to remove remaining cells. Total volume of $12-\mathrm{ml}$ extraction solution containing cells was freeze dried and stored at $-80^{\circ} \mathrm{C}$ until use. Directly before measurements, the samples were suspended in $100 \mu 10 \mathrm{mM}$ ammonium acetate (volume normalized depending on $\mathrm{OD}_{578}$ before harvesting). For relative quantification via LC/MS $1 \mathrm{mM}$ 2-Cl-benzoyl-CoA was added to the samples.

Prenylated FMN was extracted from $1 \mathrm{~g}$ frozen D. cetonica cells. Cells were anaerobically lysed as 
described and ultracentrifuged ( $\left.1 \mathrm{~h}, 200,000 \mathrm{~g}, 4^{\circ} \mathrm{C}\right)$. Supernatant was incubated with $50 \%$ aqueous acetonitrile $(\mathrm{v} / \mathrm{v})$ followed by incubation for $10 \mathrm{~min}$ at $70^{\circ} \mathrm{C}$. The mix was centrifuged and resulting supernatant was freeze dried. The product was dissolved in $100 \mu 10 \%$ acetonitrile/ $\mathrm{ddH}_{2} \mathrm{O}(\mathrm{v} / \mathrm{v})$ and analysed via LC/MS. Absolute prFMN concentrations were estimated in reference to a calibration curve using FMN as a standard.

\section{Mass spectrometry-based proteome analyses}

For proteome analysis cells were grown in biological replicates ( $n=6$ for phthalate and benzoate, and $n=5$ for butyrate). Preparation of protein samples from cells for mass spectrometric analyses including separation by SDS-PAGE and tryptic digestion were as previously described (Warnke et al., 2017). The resulting peptides were separated by UHPLC (Ultimate 3000, Dionex/ Thermo Fisher Scientific) using a C18 column with reverse phase $(25 \mathrm{~cm})$ in a linear gradient from $2 \%$ to $55 \%$ acetonitrile in $0.1 \%$ formic acid (v/v) (120 min). Proteome analysis was performed using a $\mathrm{Q}$ Exactive $\mathrm{HF}$ mass spectrometer (Thermo Fisher Scientific). Proteome Discoverer (version 1.4.1.14 Thermo Scientific) was used for protein identification, and the acquired MS/MS spectra were searched with SEQUEST HT against NCBI available Desulfosarcina cetonica database. Only peptides with a false discovery rate $<0.01$ calculated by Percolator and peptide rank = 1 were considered as identified. The abundance of one protein was quantified using the average of the top-3 peptides assigned to this protein.

\section{Computational analyses}

Gene cluster of Desulfosarcina cetonica was analysed using SnapGene@ (version 3.2.1, GSL Biotech LLC) and $\mathrm{NCBI}$ available shotgun genome sequences of Desulfosarcina cetonica. Homology of the corresponding gene products was analysed using the blastp algorithm (Altschul et al., 1990).

\section{Acknowledgements}

This work was funded by the German research council (BO 1565/16-1).

\section{References}

Altschul, S.F., Gish, W., Miller, W., Myers, E.W., Lipman, D.J. (1990) Basic local alignment search tool. J Mol Biol 215: 403-410.

Anantharaman, K., Brown, C.T., Hug, L.A., Sharon, I., Castelle, C.J., Probst, A.J., et al. (2016) Thousands of microbial genomes shed light on interconnected biogeochemical processes in an aquifer system. Nat Commun 7: 13219.

Benjamin, S., Pradeep, S., Josh, M.S., Kumar, S., and Masai, E. (2015) A monograph on the remediation of hazardous phthalates. J Hazard Mater 298: 58-72.

Bergmann, M., Tekman, M.B., and Gutow, L. (2017) Marine litter: sea change for plastic pollution. Nature 544: 297.

Boll, M., Löffler, C., Morris, B.E.L., and Kung, J.W. (2014) Anaerobic degradation of homocyclic aromatic compounds via arylcarboxyl-coenzyme a esters: organisms, strategies and key enzymes. Environ Microbiol 16: 612-627.

Buckel, W., Kung, J.W., and Boll, M. (2014) The benzoylcoenzyme a reductase and 2-hydroxyacyl-coenzyme a dehydratase radical enzyme family. Chembiochem 15: 2188-2194.

Caldwell, J.C. (2012) DEHP: genotoxicity and potential carcinogenic mechanisms-a review. Mutat Res 751: 82-157.

Chang, B.V., Liao, C.S., and Yuan, S.Y. (2005) Anaerobic degradation of diethyl phthalate, di-n-butyl phthalate, and di-(2-ethylhexyl) phthalate from river sediment in Taiwan. Chemosphere 58: 1601-1607.

Cousins, I.T., Mackay, D., and Parkerton, T.F. (2003) Physical-chemical properties and evaluative fate modelling of phthalate esters. In Series Anthropogenic Compounds, Hutzinger, O., and Staples, C.A. (eds). Berlin, Heidelberg: Springer Berlin Heidelberg, pp. 57-84.

DiDonato, R.J., Jr., Young, N.D., Butler, J.E., Chin, K.J., Hixson, K.K., Mouser, P., et al. (2010) Genome sequence of the deltaproteobacterial strain NaphS2 and analysis of differential gene expression during anaerobic growth on naphthalene. PLoS One 5: e14072.

Eaton, R.W., and Ribbons, D.W. (1982) Metabolism of dibutylphthalate and phthalate by micrococcus sp. strain 12B. $J$ Bacteriol 151: 48-57.

Ebenau-Jehle, C., Mergelsberg, M., Fischer, S., Bruls, T., Jehmlich, N., von Bergen, M., and Boll, M. (2017) An unusual strategy for the anoxic biodegradation of phthalate. ISME J 11: 224-236.

Fuchs, G., Boll, M., and Heider, J. (2011) Microbial degradation of aromatic compounds - from one strategy to four. Nat Rev Microbiol 9: 803-816.

Galushko, A., and Rozanova, E.P. (1991) Desulfobacterium cetonicum sp. nov.: a sulfate-reducing bacterium which oxidizes fatty acids and ketones. Microbiology 60: 742-746.

Gao, D.-W., and Wen, Z.-D. (2016) Phthalate esters in the environment: a critical review of their occurrence, biodegradation, and removal during wastewater treatment processes. Sci Total Environ 541: 986-1001.

Giam, C.S., Atlas, E., Powers, J.M.A., and Leonard, J.E. (1984) Phthalate Esters. Anthropogenic Chemicals. Berlin, Germany: Springer-Verlag, pp. 67-142.

Haward, M. (2018) Plastic pollution of the world's seas and oceans as a contemporary challenge in ocean governance. Nat Commun 9: 667.

Huang, J., Nkrumah, P.N., Li, Y., and Appiah-Sefah, G. (2013) Chemical behavior of phthalates under abiotic conditions in landfills. Rev Environ Contam Toxicol 224: 39-52.

Janssen, P.H., and Schink, B. (1995a) Metabolic pathways and energetics of the acetone-oxidizing, sulfate-reducing bacterium Desulfobacterium cetonicum. Arch Microbiol 163: $188-194$. 
Janssen, P.H., and Schink, B. (1995b) Pathway of butyrate catabolism by Desulfobacterium cetonicum. J Bacteriol 177: 3870-3872.

Junghare, M., Spiteller, D., and Schink, B. (2016) Enzymes involved in the anaerobic degradation of ortho-phthalate by the nitrate-reducing bacterium Azoarcus sp. strain PA01. Environ Microbiol 18: 3175-3188.

Junghare, M., Spiteller, D., and Schink, B. (2019) Anaerobic degradation of xenobiotic isophthalate by the fermenting bacterium Syntrophorhabdus aromaticivorans. ISME J 13: 1252-1268.

Kleerebezem, R. (1999) Energetics of product formation during anaerobic degradation of phthalate isomers and benzoate. FEMS Microbiol Ecol 29: 273-282.

Kleerebezem, R., Hulshoff Pol, L.W., and Lettinga, G. (1999) Anaerobic degradation of phthalate isomers by methanogenic consortia. Appl Environ Microbiol 65: 1152-1160.

Koelschbach, J.S., Moutakki, H., Merl-Pham, J., Arnold, M. E., and Meckenstock, R.U. (2019) Identification of naphthalene carboxylase subunits of the sulfate-reducing culture N47. Biodegradation 30: 147-160. https://doi.org/10. 1007/s10532-019-09872-z

Kung, J.W., Baumann, S., von Bergen, M., Müller, M. Hagedoorn, P.L., Hagen, W.R., and Boll, M. (2010) Reversible biological birch reduction at an extremely low redox potential. J Am Chem Soc 132: 9850-9856.

Leys, D. (2018) Flavin metamorphosis: cofactor transformation through prenylation. Curr Opin Chem Biol 47: 117-125.

Leys, D., and Scrutton, N.S. (2016) Sweating the assets of flavin cofactors: new insight of chemical versatility from knowledge of structure and mechanism. Curr Opin Struct Biol 41: 19-26.

Liang, D.-W., Zhang, T., Fang, H.H.P., and He, J. (2008) Phthalates biodegradation in the environment. Appl Microbiol Biotechnol 80: 183-198.

Liu, S.-M., and Chi, W.-C. (2003) $\mathrm{CO}_{2}-\mathrm{H}_{2}$-dependent anaerobic biotransformation of phthalic acid isomers in sediment slurries. Chemosphere 52: 951-958.

Liu, S.M., Lin, Y.L., and Chi, W.C. (2005a) The effects of benzoate, cyclohex-1-ene carboxylate, and cyclohexane carboxylate on biotransformation of o-phthalate in sediment slurries under sulfate-reducing conditions. Chemosphere 59: 41-48.

Liu, S.M., Lin, Y.L., and Tsai, T.L. (2005b) Growth dynamics of major microbial populations during biodegradation of o-phthalate in anaerobic sediment slurries under a $\mathrm{CO}_{2} / \mathrm{H}_{2}$ atmosphere. Chemosphere 59: 91-98.

Mergelsberg, M., Willistein, M., Meyer, H., Stark, H.J., Bechtel, D.F., Pierik, A.J., and Boll, M. (2017) Phthaloylcoenzyme a decarboxylase from Thauera chlorobenzoica: the prenylated flavin-, $\mathrm{K}(+)$ - and $\mathrm{Fe}(2+)$-dependent key enzyme of anaerobic phthalate degradation. Environ Microbiol 19: 3734-3744.

Mergelsberg, M., Egle, V., and Boll, M. (2018) Evolution of a xenobiotic degradation pathway: formation and capture of the labile phthaloyl-CoA intermediate during anaerobic phthalate degradation. Mol Microbiol 108: 614-626.

Musat, F., Galushko, A., Jacob, J., Widdel, F., Kube, M., Reinhardt, R., et al. (2009) Anaerobic degradation of naphthalene and 2-methylnaphthalene by strains of marine sulfate-reducing bacteria. Environ Microbiol 11: 209-219.
Net, S., Sempéré, R., Delmont, A., Paluselli, A., and Ouddane, B. (2015) Occurrence, fate, behavior and ecotoxicological state of phthalates in different environmental matrices. Environ Sci Technol 49: 4019-4035.

Nomura, Y., Nakagawa, M., Ogawa, N., Harashima, S., and Oshima, Y. (1992) Genes in PHT plasmid encoding the initial degradation pathway of phthalate in Pseudomonas putida. J Ferment Bioeng 74: 333-344.

Nozawa, T., and Maruyama, Y. (1988) Anaerobic metabolism of phthalate and other aromatic compounds by a denitrifying bacterium. J Bacteriol 170: 5778-5784.

Payne, K.A.P., White, M.D., Fisher, K., Khara, B., Bailey, S. S., Parker, D., et al. (2015) New cofactor supports $\alpha, \beta$-unsaturated acid decarboxylation via 1,3-dipolar cycloaddition. Nature 522: 497-501.

Peters, F., Rother, M., and Boll, M. (2004) Selenocysteinecontaining proteins in anaerobic benzoate metabolism of Desulfococcus multivorans. J Bacteriol 186: 2156-2163.

Qiu, Y.-L., Sekiguchi, Y., Hanada, S., Imachi, H., Tseng, I.-C., Cheng, S.-S., et al. (2006) Pelotomaculum terephthalicum sp. nov. and Pelotomaculum isophthalicum sp. nov.: two anaerobic bacteria that degrade phthalate isomers in syntrophic association with hydrogenotrophic methanogens. Arch Microbiol 185: 172-182.

Rabus, R., Nordhaus, R., Ludwig, W., and Widdel, F. (1993) Complete oxidation of toluene under strictly anoxic conditions by a new sulfate-reducing bacterium. Appl Environ Microbiol 59: 1444-1451.

Rabus, R., Kube, M., Heider, J., Beck, A., Heitmann, K., Widdel, F., and Reinhardt, R. (2005) The genome sequence of an anaerobic aromatic-degrading denitrifying bacterium, strain EbN1. Arch Microbiol 183: 27-36.

Rabus, R., Boll, M., Heider, J., Meckenstock, R.U., Buckel, W., Einsle, O., et al. (2016) Anaerobic microbial degradation of hydrocarbons: from enzymatic reactions to the environment. $J$ Mol Microbiol Biotechnol 26: 5-28.

Rabus, R., Wohlbrand, L., Thies, D., Meyer, M., ReinholdHurek, B., and Kampfer, P. (2019) Aromatoleum gen. Nov., a novel genus accommodating the phylogenetic lineage including Azoarcus evansii and related species, and proposal of Aromatoleum aromaticum sp. nov., Aromatoleum petrolei sp. nov., Aromatoleum bremense sp. nov., Aromatoleum toluolicum sp. nov. and Aromatoleum diolicum sp. nov. Int J Syst Evol Microbiol 69: 982-997.

Schauder, R., Eikmanns, B., Thauer, R.K., Widdel, F., and Fuchs, G. (1986) Acetate oxidation to $\mathrm{CO}_{2}$ in anaerobic bacteria via a novel pathway not involving reactions of the citric acid cycle. Arch Microbiol 145: 162-172.

Schmid, G., Rene, S.B., and Boll, M. (2015) Enzymes of the benzoyl-coenzyme a degradation pathway in the hyperthermophilic archaeon Ferroglobus placidus. Environ Microbiol 17: 3289-3300.

Taylor, B.F., and Ribbons, D.W. (1983) Bacterial decarboxylation of 0 -phthalic acids. Appl Environ Microbiol 46: 1276-1281.

Tiedt, O., Fuchs, J., Eisenreich, W., and Boll, M. (2018) A catalytically versatile benzoyl-CoA reductase, key enzyme in the degradation of methyl- and halobenzoates in denitrifying bacteria. J Biol Chem 293: 10264-10274.

Warnke, M., Jacoby, C., Jung, T., Agne, M., Mergelsberg, M., Starke, R., et al. (2017) A patchwork pathway for 
3612

oxygenase-independent degradation of side chain containing steroids. Environ Microbiol 19: 4684-4699.

White, M.D., Payne, K.A.P., Fisher, K., Marshall, S.A., Parker, D., Rattray, N.J.W., et al. (2015) UbiX is a flavin prenyltransferase required for bacterial ubiquinone biosynthesis. Nature 522: 502-506.

Wöhlbrand, L., Jacob, J.H., Mussmann, M., Jarling, R., Beck, A., Amann, R., et al. (2013) Complete genome, catabolic subproteomes and key-metabolites of Desulfobacula toluolica Tol2, a marine, aromatic compound-degrading, sulfatereducing bacterium. Environ Microbiol 15: 1334-1355. 